\title{
A relação entre a positividade do trabalho e a submissão do indivíduo à realidade: elementos para a reflexão da Psicologia
}

\author{
Juliana de Castro Chaves ${ }^{1}$ \\ Faculdade de Educação da Universidade Federal de Goiás (Goiás, GO)
}

\begin{abstract}
Este artigo é resultado de pesquisa teórica em que se discutem os elementos necessários para a análise crítica de algumas problematizações do trabalho predominantes no mundo atual. Seu objetivo é oferecer bases para a apreensão do trabalho nas relações sociais concretas e para a reflexão sobre afirmativas que fazem apologia ao trabalho. Para tanto, são desenvolvidas as contribuições de Marx e de Freud incorporadas pela Teoria Crítica da Sociedade, vinculada à Escola de Frankfurt, especialmente por Marcuse. Nessa discussão, pode-se afirmar que a relação estabelecida por Marx entre essência e existência e entre natureza e história indica que o conceito de trabalho não é supra-histórico e, ainda, que o olhar otimista sobre o trabalho apresenta inconsistências, pois faz uma apreensão imediata de suas conquistas, realiza uma microanálise desconectada das contradições da sociedade capitalista e tenta resolver o conflito entre capital e trabalho por meio da harmonização das relações.
\end{abstract}

Palavras-chave: Trabalho, Psicologia, Teoria Crítica.

The relationship between work positivity and the individual's submission to reality: elements to Psychology reflection

This paper is the result of a theoretical research in which the elements needed for the critical analysis of some work problematizations that prevail in the current world are discussed. It aims to offer bases for the apprehension of work in the concrete social relations and for the reflection on the statements for an apology to work. For this, contributions by Marx and Freud incorporated by the Critical Theory of Society are developed, connected to the Frankfurt School, especially by Marcuse. In this discussion, one may claim that the relationship established by Marx between essence and existence and between nature and history indicates that the concept of work isn't suprahistorical and, also, that the optimistic view on work presents inconsistencies, since it sets up an immediate apprehension of its conquests, providing a microanalysis disconnected from the contradictions of the capitalist society, and it tries to solve the conflict between capital and work by harmonizing the relationships.

Keywords: Work, Psychology, Critical Theory.

\section{Introdução}

$\mathrm{E}_{\mathrm{E}}^{\mathrm{se}}$ ste artigo almeja desenvolver algumas contribuições da Teoria Crítica da Sociedade da Escola de Frankfurt, especialmente de Marcuse, autor que mais elaborou textos específicos sobre o trabalho, para a reflexão sobre algumas problematizações atuais do trabalho. Embora os autores da Escola de Frankfurt apresentem muitas diferenciações, eles estavam unidos na tentativa de compreender como era possível que a maioria da população, nos países industrializados, pensasse e agisse em um sentido que a oprimia (Rouanet, 2001). Essa pergunta estava relacionada à tentativa de entender os elementos que sustentavam a dominação e a racionalidade irracional da sociedade capitalista.

Na tentativa de compreender os fenômenos, os frankfurtianos estabelecem uma relação dialógica entre Marx e Freud, e não uma síntese desses dois autores. Marcuse (1941/1978) demonstra que, para Marx, a liberdade e a felicidade estão obstruídas na sociedade capitalista e

1 Mestre em Psicologia Social pela Universidade Federal de Minas Gerais. Doutora em Psicologia Social pela Pontifícia Universidade Católica de São Paulo. Professora da Faculdade de Educação da Universidade Federal de Goiás. Membro da direção da Regional Abrapso Centro-Oeste. 
que o sofrimento e a submissão têm suas raízes na própria história da sociedade. O pensamento marxiano evidencia que a subjetividade depende das relações concretas de produção e que a emancipação do homem de um estado de minoridade exige alterações nas condições concretas de existência e crítica da formação direcionada pela lógica do trabalho. Para Adorno (1955/1986a), o grande legado freudiano foi reconhecer, ao estudar as profundezas da mente e da singularidade humana, a mutilação social dentro do próprio indivíduo, ou seja, as condições subjetivas da "irracionalidade" objetiva. Mesmo apresentando diferenciações, Marx e Freud são importantes para a compreensão da relação entre indivíduo e sociedade. $O$ primeiro, ao analisar e criticar a objetividade, defrontou-se com a subjetividade, e o segundo, ao se debruçar sobre questões subjetivas, o fez de maneira tão profunda que acabou tratando da objetividade social. Desse modo, os autores da Teoria Crítica da Escola de Frankfurt oferecem elementos para a realização de uma Psicologia Social crítica que desvela a aparência do real, que analisa a constituição do indivíduo mediada pelo trabalho na sociedade capitalista.

Mesmo que a questão do trabalho seja bastante discutida, ela ainda é polêmica e repleta de controvérsias. Muitas ${ }^{2}$ problematizações realizadas pela Psicologia apresentam o trabalho como um fenômeno que faz parte do processo evolutivo de humanização. Não é raro perceber uma divisão nos textos produzidos. Inicialmente, o trabalho é abordado como atividade, como parte da inevitabilidade humana, depois, quando se refere às condições em que se realiza, é ligado ao sofrimento. Outras apreensões tematizam o trabalho como conceito e como realização, como centro da organização da sociedade e dos homens e como alienação. Em geral, a maioria dos debates apropria-se das ideias de Marx para justificar a concepção de trabalho, mas perde a tensão apresentada por ele entre essência e existência e natureza e história e, por isso, realizam uma análise dicotômica, que separa conceito e realidade no que diz respeito à análise do trabalho. Dessa forma, justifica-se a ideia de trabalho como algo dado, com uma ontologia essencialmente positiva, apreensão que faz perpetuar a submissão do indivíduo à realidade. Todas essas afirmativas apontam para a necessidade de se discutir a racionalidade do trabalho à luz da Teoria Crítica da Sociedade da Escola de Frankfurt, que tem tido pouca visibilidade no debate sobre o trabalho, com a intenção de contribuir para a compreensão desse fenômeno na atualidade. Desse modo, algumas afirmativas serão discutidas a seguir.

\section{Predomínio da ontogênese positiva do trabalho}

Será que é possível falar em uma ontogênese unicamente positiva do trabalho, falar do trabalho como constitutivo da liberdade do ser humano? Para analisar essas questões, é fundamental refletir sobre como o trabalho vem ocorrendo ao longo do tempo. Pode-se afirmar que, desde os primórdios da civilização, o trabalho vem acompanhado de sofrimento, de sacrifício, de recusa da fruição, de subserviência e de dominação, o que oferece elementos que preparam a racionalidade necessária para fazer valer os avanços do modo de produção atual. No capitalismo, o trabalho entrelaça-se à mais-valia, à propriedade privada, à alienação, à mercadoria, ao fetiche e à reificação.

Para entender a contribuição de Marx e analisar as contradições do trabalho, é necessário realçar o verdadeiro sentido do acerto de contas que ele estabeleceu com a base da problemática filosófica de Hegel, e não dividir o pensamento de Marx em fases filosófica e

\footnotetext{
2 Estamos referindo-nos a textos do campo da Psicologia que tomam como base a teoria de Marx, mas que enfatizam apenas uma ontologia positiva, esquecendo que, na relação entre essência e existência e natureza e história, o próprio autor aponta a negatividade do trabalho, o processo de desumanização do homem e sua reificação, processos que dificultam a emancipação humana. Esses textos desenvolvem predominantemente uma microanálise que discute os elementos perversos do capitalismo em determinadas funções que o trabalhador exerce e têm a intenção de valorizar o conhecimento, a autonomia e a criatividade do trabalhador, sem estabelecer uma reflexão crítica entre o enaltecimento dessas características e competências e as exigências do capitalismo atual, decorrentes da mudança no modo produtivo.
} 
econômica e prática revolucionária. Segundo Marcuse (1969/1981), a dialética marxiana reconhece o valor de Hegel por ele compreender a importância do trabalho na "autoprodução do homem como processo" (Marx, 1844/2004, p. 123). No entanto, ela realiza a crítica e a superação de Hegel, uma vez que ele analisa apenas o aspecto positivo do trabalho. Assim, "о trabalho que Hegel unicamente reconhece é o abstratamente espiritual" (Marx, 1844/2004, p. 124), que não leva em conta a base material do trabalho na relação do homem consigo mesmo na natureza. As categorias de Marx são "ao mesmo tempo negativas e positivas: elas apresentam uma situação negativa à luz de uma solução positiva, revelando a verdadeira situação da sociedade. [...] Este duplo conteúdo determina toda a análise [...] do processo de trabalho" (Marcuse, 1941/1978, p. 271).

Para Marcuse (1969/1981), o não aprofundamento da contribuição de Marx gera tanto uma interpretação enviesada de suas categorias quanto das de Engels, o que propicia a dominação e a hipostasia do trabalho, que transforma a palavra ou o conceito em substância, ou seja, em um ente que abandona a cisão, as contradições evidenciadas empiricamente na realidade, dificultando a capacidade de reflexão (Abbagnano, 2003).

De acordo com a interpretação de Marcuse (1969/1981), Marx aponta as contradições da sociedade capitalista que impedem o surgimento do indivíduo autônomo e feliz. Para realizar essa tarefa, o pensamento de Marx analisa a relação homem, natureza e sociedade e associa o trabalho à base material de toda e qualquer sociedade - as relações entre os próprios homens -, oferecendo subsídios para o entendimento de como a constituição humana possui uma natureza histórica. Por intermédio do trabalho, o homem objetiva-se. Cabe, então, analisar como se dá a objetivação-trabalho nas condições concretas.

O trabalho é uma atividade na qual se relacionam homem e natureza. A natureza não deve ser compreendida como uma região totalmente separada do ser, nem somente como matéria-prima a ser transformada ou como uma essência abstrata positiva que se desenvolve na ordem do tempo e do devir, indiferente a toda história concreta e que condiciona o homem da mesma maneira que os outros seres, mas como algo que se determina na história. Se a vida é produzida segundo a natureza, não há sentido em considerar que história e natureza são manifestações separadas, como se "o homem não se achasse sempre em face de uma natureza que é histórica ou de uma história que é natural" (Marx, 1844/2004, p. 128). A essencialidade do homem na natureza é histórica, significando que

[...] a natureza que vem a ser na história humana - no ato de surgimento da história humana - é a natureza efetiva do homem, por isso a natureza, assim como vem a ser por intermédio da indústria, ainda que em figura estranha, é a natureza antropológica verdadeira (Marx, 1844/2004, p. 112).

Essa perspectiva abre espaço para a avaliação da objetivação verdadeira do homem. No tocante à relação entre natureza e história, é possível conceber a constituição do homem ao longo do tempo e, ainda, estabelecer a crítica. Marcuse (1969/1981, p. 33) afirma que Marx apontou a facticidade histórica, a inversão e o ocultamento que a humanidade assumiu no capitalismo com base na exteriorização e na alienação quando afirmou que "o trabalho não é 'atividade livre', autorrealização universal e livre do homem, e sim sua escravidão e desrealização; o trabalho não é o homem na totalidade de suas manifestações vitais”. De acordo com Marx (1844/2004, p. 83), "o trabalho externo, o trabalho no qual o homem se exterioriza, é um trabalho de autossacrifício, de mortificação". A alienação rompe a relação do sujeito com o objeto "e compreende quatro aspectos: o homem se aliena dos produtos de seu trabalho, do processo de seu trabalho, de seu próprio ser e dos outros homens convertendo o trabalho em pura exteriorização" (Resende, 2001, p. 517). Assim, ele se transforma em coisa alheia que pertence a alguém, que é conduzido por um outro. 
No trabalho alienado, "a existência do homem não mais se transforma em meio de sua autorrealização" (Marcuse, 1969/1981, p. 33-34), pelo contrário, a imposição de ter de trabalhar ou morrer à míngua traduz-se em labuta, em insegurança e em temor para a maioria das pessoas, reduzindo a perspectiva da vida universal a um meio de vida individual. $\mathrm{Na}$ sociedade capitalista, o produto do trabalho é uma mercadoria que, por suas propriedades, satisfaz as necessidades humanas diretamente, como meio de subsistência, objeto de consumo, ou indiretamente, como meio de produção. A mercadoria encobre as características sociais do próprio trabalho dos homens e torna os homens anônimos (Resende, 2001). Nesse sentido, a mercadoria faz que as características humanas apareçam como características materiais e propriedades sociais inerentes aos produtos do trabalho, caracterizando o fetiche.

Segundo Marx (1844/2004), a relação estabelecida entre os homens assume a forma fantasmagórica de uma relação entre coisas, como se os produtos do cérebro humano fossem dotados de vida própria, figuras autônomas que mantêm relações entre si e com os seres humanos, sem deles depender. No fetiche, "aquilo que é objeto de mediação é tomado pela aparência de imediaticidade num movimento pelo qual o valor de uso, mera forma fenomênica imprescindível às mercadorias na sociedade capitalista, é tomado pelo valor de troca" (Resende, 2001, pp. 520-521).

Esse processo atinge o íntimo do indivíduo, ocorrendo a reificação da consciência. De acordo com Resende (2001, p. 524), a reificação, de acordo com Lukács, apresenta três aspectos: a) perda do sentido da totalidade em uma realidade cuja unidade se esfumou pela fragmentação em operações paralelas, calculadas e parciais; separação e fragmentação da sociedade em aspectos isolados e, ainda, acidentalidade, irracionalidade e contraste dos elementos que constituem a totalidade; b) progressiva racionalização, cálculo e previsibilidade de todos os setores da vida que culminam em uma atitude contemplativa do indivíduo ante a realidade fragmentada; c) estrutura subjetiva que se produz em face da universalização da estrutura mercantil; pela primeira vez, pode-se falar em uma consciência unitária para o conjunto da sociedade. Pode-se afirmar que a passagem da alienação para o fetiche e dele para a reificação ajuda a compreender como a racionalidade do trabalho se desenvolve e determina a consciência.

Marcuse (1969/1981) afirma que o trabalho não concretiza a liberdade inferior e nem a liberdade superior descrita por Marx. A liberdade inferior, mais ligada ao reino da necessidade, consiste na regulação racional do intercâmbio material com a natureza, em uma organização social consciente, uma superação da penúria exterior não é realizada, pois ela pressupõe intercâmbio com a natureza e condições dignas e adequadas à natureza humana. A liberdade superior, a do desenvolvimento das potencialidades humanas como objetivo em si, que se situa além da esfera da produção material e que depende da organização racional da sociedade, também não é realizada. Para o autor,

[...] a ideia de Marx de uma sociedade racional implica a existência de uma ordem em que o princípio da organização social não seja a universalidade do trabalho, mas a satisfação universal de todas as potencialidades individuais que constituem o princípio da organização social. Ele contempla uma sociedade que dá a cada um, não segundo seu trabalho, mas segundo suas necessidades (Marcuse, 1941/1978, p. 269).

O trabalho, pelo contrário, associa-se à dominação, quer da natureza, quer dos homens, que também são natureza; e da natureza, a dominação estende-se para seus herdeiros sociais (os homens). $\mathrm{O}$ ideal seria que o trabalho conseguisse engrandecer o homem, mas deve-se considerar que ele não tem realizado essa promessa. $O$ trabalho, no capitalismo, não pode ser descolado do capital, de modo que a crítica do capital é a crítica do trabalho e vice-versa. Segundo Marcuse (1941/1978, p. 268), 
[...] a abolição do proletariado equivale, portanto, à abolição do trabalho como tal. Marx faz disto uma formulação expressa quando fala da realização da revolução. As classes devem ser abolidas "pela abolição da propriedade e do próprio trabalho". Em outro lugar, Marx afirma a mesma coisa: "A revolução comunista se dirige contra o modo precedente de atividade, acaba com o trabalho". E, outra vez, "a questão não é a de libertação, mas a de abolição do trabalho". A questão não é da libertação do trabalho porque o trabalho já é "livre"; o trabalho livre é a conquista da sociedade capitalista. O comunismo só pode curar os "males" do burguês e a miséria do proletário pela extinção da sua causa, isto é, do "trabalho".

De acordo com Marcuse (1969/1981, p. 36), "se a facticidade chegou até a inteira inversão da essência humana, a superação radical desta facticidade é a tarefa pura e simplesmente". Assim, a visão da essência do homem deve transformar-se em impulso para a revolução radical, pois, no capitalismo, há a catástrofe da essência humana, posto que a objetivação não é fonte de reconhecimento, pelo contrário, é perda de si mesmo. Nesse caso, reconhecendo a situação histórico-social da objetivação, pode-se encontrar força para a revolução.

Segundo Horkheimer e Adorno (1947/1985), a ligação entre trabalho e liberdade fazia sentido quando a escassez era uma realidade a ser superada. $O$ trabalho e a dominação foram importantes para a criação de condições objetivas de libertação; porém, depois que essas instâncias cumpriram seu objetivo, não deveriam ter tornado-se estruturas fixas, já que foi a história que gerou a estrutura e não a estrutura que gerou a história.

Desse modo, a ideia de que a racionalidade humana está localizada naturalmente na ontologia do trabalho, só apontando seu caráter positivo, deve ser questionada. Supor a existência, a liberdade do ser, por um critério ontológico é metafísico e baseado em critérios subjetivos. A relação do indivíduo com o trabalho é algo objetivo, que se dá em uma ação conjunta com base na apropriação da realidade. O ser faz-se na história e constrói a história com base no existente, por isso, é necessário entender o trabalho na sociedade que o cria.

Para Marcuse (1941/1978), Marx considerava as condições de trabalho percebendo a sua negação em uma sociedade livre, o que não significava que o trabalho não possuísse qualidades de progresso, porém, sua negação deveria ser um princípio motor e criador. $\mathrm{O}$ trabalho poderia ser uma atividade prazerosa se perdesse o caráter de autoconservação e adquirisse um fim em si, tendo como atrativo principal o lúdico, o prazer. Nessa perspectiva,

Marx [...] prefigura um modo futuro de trabalho tão diferente do modo predominante, que ele hesita em usar a mesma palavra "trabalho", para designar o processo material da sociedade capitalista e o da sociedade comunista. Ele usa o termo "trabalho para significar o que o capitalismo na verdade entende que o trabalho, em última análise, signifique, ou seja, aquela atividade que cria a mais-valia na produção de mercadorias, ou que "produz capital". Outras espécies de atividade não são "trabalho produtivo" no sentido próprio. O trabalho significa, pois, que se nega ao indivíduo que trabalha o desenvolvimento livre e universal, sendo claro que, neste caso, a libertação do indivíduo é, ao mesmo tempo, a negação do trabalho (Marcuse, 1941/1978, pp. 268-269).

O esclarecimento deveria tornar o homem livre do trabalho. Essa liberdade não é utópica, pois já existem condições objetivas para tal. A necessidade do trabalho para a sobrevivência é uma mentira manifesta, pois o acúmulo de conhecimentos e o avanço tecnológico já oferecem condições de eliminar a miséria da Terra. No entanto, o progresso não cumpriu sua promessa, ocorrendo a regressão da sociedade, que implica que os problemas relativos à pobreza são de cunho político, e não econômico. 


\section{Separação entre o conceito e a realização do trabalho}

A perda da tensão entre essência e existência apresentada por Marx também faz que algumas problematizações sobre o trabalho realizem a separação entre o conceito e a realização do trabalho e atribuam ao primeiro a emancipação, e outras separam as concepções de labor (animal) e work (trabalho humano), situando a análise no âmbito da origem da palavra ou da atribuição de esforço para o trabalho não humano e de criatividade para o trabalho humano. Pode-se observar que é equivocado separar essas duas instâncias, pois a distinção nem sempre é tão nítida. Na tradução que Lafer (1989/2002) faz da poesia de Hesíodo (1989/2002), em Os trabalhos e os dias, obra considerada base para a concepção de formação da cultura ocidental, a palavra érgon recebe o significado de trabalho mais amplo e não apenas de trabalho agrícola e, em alguns momentos, érgon (trabalho) e pónos (trabalho árduo, fadiga), embora distintos, aparecem entrelaçados na poesia.

Arendt (1958/2004, citada por Lafer, 1989/2002, pp. 61-62), ao investigar a linguagem em sua historicidade como constitutiva do repertório da experiência humana, pesquisou a diferença entre labor e work, segundo o registro da diferença entre érgon e pónos, e estabeleceu uma diferenciação nítida entre labor (labor), atividade do animal laborans, baseada nas necessidades de subsistência do ciclo biológico da vida, e work (trabalho), atividade do homo faber, não necessariamente contida no ciclo vital da espécie por meio da qual coisas extraídas da natureza se convertem em objeto de uso. Pode-se notar, entretanto, que a discriminação e a valoração de érgon (trabalho) em alguns momentos não são tão nítidas no mito de Pandora, descrito por Hesíodo, obra que a autora utilizou como referência inicial para estabelecer a caracterização entre atividade humana e atividade animal, mostrando que é perigoso resolver por definições as contradições entre as duas atividades.

Em alguns momentos, a origem de érgon apresenta certa ambiguidade, podendo o termo ser ora considerado positivo, ora negativo, ao contrário de pónos (trabalho árduo, fadiga) que, por sua vez, é sempre considerado um dos males que sai de dentro do jarro de Pandora e, em decorrência, já se apresenta de imediato como algo ruim. Segundo Lafer (1989/2002), embora érgon apareça predominantemente na poesia com uma conotação positiva, o trabalho também aponta uma conotação negativa, pois é uma contingência humana originada da resposta de Zeus, por ter sido enganado, já que anteriormente, em um tempo harmônico, o trabalho, por não haver a condição humana, não existia. Mesmo que Hesíodo (1989/2002) enalteça o trabalho, não está satisfeito com seu tempo, pois apresenta descontentamento com a dura atualidade em que vive (Idade do Fogo) e nostalgia pela perda da antiga Idade do Ouro, quando não existia trabalho.

Da mesma forma, se o trabalho for tomado ao longo do tempo, ele se vincula muito mais aos atos de comer, beber, procriar, habitar, funções meramente animais que se tornam finalidades últimas da vida. Nesse sentido, o trabalhador só se sente livre em suas funções animais, as quais, na atual conjuntura, já se tornam difíceis de ser realizadas em plenitude, e se sente animal em suas funções propriamente humanas (Marx, 1844/2004).

Desse modo, a separação dicotômica entre os dois exercícios de trabalho resulta em um nominalismo perigoso. $\mathrm{O}$ conhecimento sustentado pelo nominalismo partilha a forma de tratar o trabalho como uma convenção universal, algo abstrato que relega as oposições objetivas e encobre as contradições a ponto de negá-las. Essa abstração afeta o conteúdo porque elimina do sujeito o que não corresponde ao conceito puro (Chaves, 2007). 


\section{Trabalho: atividade responsável pelo surgimento da espécie humana}

Segundo Pedrosa (2003), a apropriação que alguns fazem dos textos de Engels também contribui para a apologia do trabalho e para a dominação da natureza. Engels (1870/2000) enfatiza, em seu texto inacabado Humanização do macaco pelo trabalho, a importância do trabalho não apenas como principal instância socializadora ou como fonte de toda riqueza, mas como categoria central da formação do homem: "O trabalho é a condição fundamental de toda a vida humana; e o é num grau tão elevado que, num certo sentido, pode-se dizer: o trabalho, por si mesmo, criou o homem" (Engels, 1870/2000, p. 215). Para Pedrosa (2003), essa obra pode receber as seguintes contestações: a tentativa de fugir do idealismo e oferecer uma base empírica dos enunciados, por via antropológica, faz que Engels aborde a formação humana e sua relação com o trabalho com metanarrativas que explicam as etapas da evolução humana como um continuum, lidando com períodos remotos, tornando as afirmações carentes da própria base empírica que apregoa.

Seguindo o raciocínio da lei de correlação do desenvolvimento descrita por Darwin, Engels (1870/2000, p. 217) afirma que o refinamento da mão e a conformação do pé, que torna possível a marcha bípede, repercutiram sobre o raio de percepção humana, aproximando os membros da sociedade e criando em cada um a consciência da utilidade da colaboração, da necessidade de dizer alguma coisa ao outro e do sentir. A criação de ferramentas para a caça e para a pesca implicou que a alimentação, que era exclusivamente vegetariana, tenha passado a incluir a ingestão de carne, o que levou à produção de outras conquistas, como o domínio do fogo, a caça e a domesticação dos animais. Assim, os homens passaram a capacitar-se para a realização de trabalhos mais complexos estabelecendo objetivos cada vez mais elevados.

De acordo com Adorno (1969/1995), explicar a cisão ou a origem do homem por meio da tese da antecedência é absurdo, pois ela eterniza a forma anterior, criando um caráter absoluto do trabalho como constitutivo do aprimoramento do homem, esquecendo que esse aspecto só pode ser concebido na história, por meio da relação com os outros. Se o trabalho foi o meio que possibilitou grande parte das transformações no homem, pode-se dizer que ele está circunscrito à pré-história e que os homens não precisam mais dele para essa constituição, pois essa diferenciação já ocorreu.

Se o trabalho foi responsável pela diferenciação entre homem e animal, pode-se dizer que ele, na atualidade, transformou-se em fim, fazendo que muitas características do homem fossem reduzidas. Se, no passado, o trabalho foi responsável pela definição da espécie, ela já se definiu, e o trabalho, baseado na dominação, só a tornou mais desumana. Como demonstrado, o que existe e já existiu é o trabalho como algo que possibilitou a sobrevivência e a dominação.

\section{Trabalho: dominação da natureza}

Outra possibilidade de equívoco na apropriação do trabalho ocorre quando a ligação entre trabalho e dominação é justificada pela ontogênese. A afirmativa de Marx que a dominação da natureza pelo trabalho é condição sine qua non para o homem se transformar em homem deve ser mais bem analisada, pois uma apropriação imediata pode passar a ideia de uma dominação perpétua e ontológica. Nesse sentido, a associação entre trabalho e dominação, quer da natureza, quer dos homens, que também são natureza, fica difícil de ser rompida (Horkheimer \& Adorno, 1947/1985).

Engels (1870/2000, p. 223) também resgata essa ideia ao afirmar que o homem, no trabalho, põe a natureza a serviço de seus fins determinados, "imprimindo-lhe as modificações 
que julga necessárias, isto é domina a Natureza”. Após elevar o homem, com base no trabalho, a um patamar superior em relação aos animais, Engels (1870/2000, p. 224) preocupado com a vingança da natureza em razão das vitórias humanas, faz a seguinte advertência:

Não podemos dominar a Natureza como um conquistador domina um povo estrangeiro, como alguém situado fora da natureza; mas sim que lhe pertencemos, com a nossa carne, nosso sangue, nosso cérebro; que estamos no meio dela; e que todo domínio sobre ela consiste na vantagem que levamos sobre os demais seres de poder chegar a conhecer suas leis e aplicá-las corretamente.

Entretanto, mesmo que para Engels (1870/2000) o homem já esteja apto a dominar e a regular sua atividade produtiva e as consequências sociais dela, isso não vem ocorrendo, porque, em seus modos de produção, ele só enxergou os efeitos úteis e mais imediatos do trabalho, descuidando das consequências que surgiram posteriormente. A apropriação da ideia do domínio da natureza leva a pensar que tanto a natureza interna quanto a externa devem ser transformadas pelo homem. Para o homem humanizar-se, ele deve desnaturalizar-se e transformar a natureza em produtos que satisfaçam suas necessidades.

"A ideia de dominação deve e pode ser questionada como forma de lidar com a natureza e como pauta de relacionamento entre indivíduos", assinala Imbrizi (2005, p. 178). A força que intenta dominar a natureza externa tem como base o não reconhecimento dos limites da natureza humana. Segundo Marx (1844/2004, pp. 112-113), "o homem rico é simultaneamente o homem carente de uma totalidade de manifestações humanas de vida. $\mathrm{O}$ homem, no qual sua efetivação própria existe como necessidade interior, como falta". Dessa forma, até a intenção de superar limites pressupõe reconhecê-los. Como o homem acha-se capaz de superar todos os limites, ele esquece sua própria natureza, que é limitada e, assim, deixa de ser humano. Como afirma Goethe (1774/2002, p. 265), "a natureza humana é limitada; ela suporta a alegria, a tristeza, a dor, até certo ponto".

Marcuse (1969/1981) aponta que o próprio Marx revelou preocupação com os efeitos perversos da dominação da natureza pelo trabalho, tanto ao discutir o caráter nocivo do progresso da agricultura capitalista para o trabalhador e para o solo como ao verificar que a expansão da indústria moderna e a subsunção do indivíduo à lógica do lucro são processos de destruição do homem e da natureza. Assim, deve-se resgatar a relação de comunicação e não de dominação entre homem e natureza, pois

[...] o homem não está na natureza, a natureza não é seu mundo exterior, ao qual ele teria que dirigir-se a partir de sua interiorização, e sim o homem é natureza; a natureza é sua "exteriorização", sua obra e sua realidade (Marcuse, (1969/1981, p. 24).

É a relação com a natureza, e não a própria natureza, que deve ser transformada. A origem do homem está na natureza e, por isso, ele deve retornar a ela para ser diferente. Desse modo, a naturalidade pertence à essência humana e, portanto, não pode ser negligenciada.

O trabalho, ao modificar a natureza, violenta-a, pois o homem a considera como um para si humano. Dessa forma, a natureza é considerada um meio, e não um outro. É a relação com a natureza que deve ser transformada, e não a natureza. Para relacionar-se com a natureza, é necessário também se submeter a ela. Quando o homem se desconhece como natureza, o próprio télos é perdido. A origem do homem está na natureza, por isso ele deve a ela retornar para ser diferente. Não é tirar a vida da natureza, como fazem aqueles que arrancam as flores dos jardins para enfeitar a pessoa amada, passando a ideia de que a efusão do sentimento por alguém pode perdoar a injustiça feita a todas as outras coisas, mas perceber a vida que pode ser manifestada na natureza para libertar a própria vida do objeto. Assim, seria possível a paz entre homem e natureza, entre sujeito e objeto, um "estado de diferenciação sem dominação no qual o diferente é compartido” (Adorno, 1969/1995, p. 184). 


\section{Possibilidade de autonomia no modo produtivo atual}

A positividade do trabalho também se encontra em textos de autores que comparam o modo produtivo taylorista-fordista com o toyotismo, naqueles que discutem a inserção do trabalho flexível, que nega a cisão entre concepção e execução, e naqueles que enaltecem a qualificação, a capacidade de pensar, de ser proativo e dinâmico, como forma de romper com a alienação. No entanto, a crença de que o conhecimento de todo o processo produtivo não gera mais alienação reduz a concepção de divisão do trabalho, tão criticada por Marx, à mera fragmentação das tarefas no interior do processo produtivo ou na separação entre concepção e execução. Esse pensamento auxilia o sentimento da nostalgia do trabalho artesanal como protótipo do trabalho qualificado. Porém, para que não se façam transferências indevidas, é necessário esclarecer o que há de específico em cada modo produtivo. $\mathrm{O}$ artesão tinha a posse dos instrumentos e dos produtos, o que permitia sua formação individual; no entanto, ele não era senhor do valor de troca de sua produção, já que seus produtos eram mercadorias fabricadas para ser vendidas no mercado.

É verdade que o trabalhador qualificado pode autogerir a empresa, autodeterminar as condições de produção e as definições de tarefas, mas elas não ficam menos heterodeterminadas no conjunto do processo social de produção, tendo em vista que se determina a própria necessidade de se autogerir, de efetivar alternativas de renda e de escolher o que produzir. Sem dúvida, a possibilidade de escolha cresceu tremendamente com o aumento das potencialidades produtivas. No entanto,

[...] antes de interpretar a multiplicação de escolhas como um aumento de liberdade, [...] devemos levar em conta a pressão inseparável desse aumento e a mudança de qualidade que é concomitante a essa nova espécie de escolha. [...] A mudança pode ser ilustrada pela diferença entre o artesão do velho tipo, que escolhia o instrumento adequado para uma elaboração delicada, e o trabalhador de hoje, que deve decidir rapidamente qual das muitas alavancas ou comutadores deve puxar (Horkheimer, 1968/2002, pp. 102-103).

É claro que "conduzir um cavalo ou dirigir um automóvel" (Horkheimer, 1968/2002, p. 102) apresentam graus de liberdade diferentes. A importância da ampliação de ofertas não pode ser subestimada; contudo, o acréscimo de liberdade trouxe uma mudança no caráter da liberdade. É como se as leis, as normas e as instruções a ser cumpridas "dirigissem o carro e não nós" (Horkheimer, 1968/2002, p. 103), substituindo a disposição para a reflexão sobre as condições objetivas que determinam esse novo modelo de indivíduo trabalhador. Embora o indivíduo acredite que está realizando escolhas, elas são completamente dirigidas pelas forças sociais que ainda atribuem ao indivíduo total responsabilidade pelas consequências dos seus atos. As escolhas geralmente diferem minimamente, mas são enaltecidas como se fossem alterar o curso inteiro da vida (Adorno, 1955/1986a).

A visão essencialista de qualificação humana que não leva em conta a dinâmica histórica do capitalismo também permite que a racionalidade do trabalho permaneça na base da coação social sobre os indivíduos, realizando o controle externo e seu autocontrole. Esse discurso apresenta uma nova roupagem a velhas práticas de dominação já utilizadas no trabalho: "São novas formas de interiorização do capital sobre o trabalho, nova pedagogia do capital que objetiva formar trabalhadores capazes de gerirem com autonomia a sua própria heteronomia" (Pedrosa, 2003, p. 186).

O rompimento com as ideias de submissão e humilhação do trabalhador também são justificadas quando se discute a necessidade da mudança do rígido controle hierárquico pela horizontalidade das relações, pela parceria, pela gestão que envolve a colaboração. A ênfase às competências e não à execução de tarefas também é enaltecida como algo formativo. $O$ preparo do indivíduo para ser empreendedor, com o desenvolvimento das potencialidades do 
protagonismo, do empoderamento, assume a mesma proposição: prepará-lo para ser autônomo. Tributária dessa ideia encontra-se a preocupação com a educação integral que visa ao pleno emprego, o cooperativismo, o associativismo, o empreendedorismo e a comercialização de serviços e não mais exige práticas estritas de treinamento operacional, imediatista, segmentado e pragmático.

Nesse contexto, antigas bandeiras ligadas à emancipação são apropriadas para que se mantenha e se amplie o vínculo entre o indivíduo e a lógica do capital. Não se pode esquecer que a ideia de cooperativas, associada à união, participação, gestão grupal, democratização de saberes e uso de matéria-prima local, acaba sendo uma medida compensatória que não aparece desligada do colapso do sistema produtor que provoca a eliminação do sistema formal, do sistema salarial (Pedrosa, 2003). Mesmo que os trabalhadores não estejam formalmente empregados, são criados outros vínculos que mantêm a relação entre indivíduo e lógica do lucro, fazendo que eles funcionem como exército de reserva para as novas relações de produção. Os indivíduos devem ser capazes de atuar sozinhos, de modo a criar alternativas de renda. Pressupõe-se que a mudança de estado de desempregado e empregado à condição de empresário, gerador de emprego e renda, traga autonomia.

Todo esse movimento gera "uma aparência de que o interesse universal só seria o interesse pelo status quo, e que o ideal seria a plena ocupação e não o interesse em libertar-se do trabalho heterônomo" (Adorno, 1947/1986b, p. 69). O indivíduo é preparado para viver em uma sociedade em permanente mudança, com novas relações de produção. Ele se torna gradativamente menos dependente de padrões absolutos de conduta, e, sendo totalmente livre, não precisa de padrões, exceto o seu próprio, que é determinado pelo modo de produção atual. Paradoxalmente, o aumento de independência conduz a um aumento de passividade (Horkheimer, 1968/2002).

Outra situação, que também ilustra o modelo de qualificação profissional, é a formação do trabalhador com o objetivo de desenvolver a mobilidade e a polivalência, resultantes da necessidade da flexibilidade das relações de produção e de maior empenho da força de trabalho, uma vez que, nas novas organizações, há menos trabalhador e muito trabalho. Ao trabalhador cabe o domínio de vários saberes e de diversas funções, além da necessidade de reestruturação de sua carreira tendo como base a aprendizagem atual e diversificada que, antes, estava submetida à rotina e à estabilidade funcional. Não é casual que o aprender a aprender venha acompanhado de um discurso que ressalta a existência de uma aceleração vertiginosa das mudanças na tecnologia, nas relações de trabalho e da produção, nos valores culturais e nas relações econômicas e políticas internacionais, não analisando profundamente a natureza e a direção dessas mudanças. No processo de produção flexível, o trabalhador precisa estar disposto a mudar constantemente de ocupações que, no fundo, apresentam a mesma racionalidade:

Se um artesão medieval pudesse adotar outro ofício, sua mudança seria muito mais radical do que a de alguém hoje que se torna sucessivamente um mecânico, um vendedor e um diretor de uma companhia de seguros. A cada vez maior uniformidade de técnicas torna cada vez mais fácil a mudança de empregos. Mas essa maior facilidade de transição de uma atividade para outra não significa que haja mais tempo para a especulação ou para os desvios dos padrões estabelecidos (Horkheimer, 1968/2002, p. 101).

Em nome da empregabilidade, "palavra que soa nova e parece que prometida a um belo futuro" (Forrester, 1997, p. 118), mas, que, na verdade, é similar à flexibilidade (que também é calcada na instabilidade), a autonomia do trabalhador é exaltada. Fragilizado, ele é preparado para estar sempre disponível para enfrentar todas as mudanças, submeter-se a todos os caprichos e à troca constante de trabalho e de empresa: "Quanto maior for a iniciativa necessitada em praticamente todos os setores da vida, maiores são as exigências de adaptação às condições mutáveis" (Horkheimer, 1968/2002, p. 101). A sociedade atual passa a impressão de que é livre, mas, na verdade, difunde um código universal que dita uma direção a ser seguida 
e um padrão de comportamento. Para o indivíduo comum, torna-se cada vez mais difícil planejar para seus herdeiros e para o seu futuro: "O indivíduo contemporâneo pode ter mais oportunidades do que seus ancestrais, mas suas perspectivas concretas têm prazo cada vez mais curto. O futuro não entra rigorosamente em suas transações" (Horkheimer, 1968/2002, p. 142). O sujeito torna-se cativo do presente que se esvai e esquece o uso das funções intelectuais pelas quais ele era capaz de transcender sua posição na realidade.

\section{Trabalho: possibilidade de prazer}

Dentre os que endossam a apologia do trabalho encontram-se, ainda, aqueles que conseguem visualizar, mesmo no trabalho alienado, mecanismos de fuga e prazer ou espaços para a constituição de uma consciência crítica (Crochík, 2003). Nesse quesito, é fundamental resgatar as contribuições de Horkheimer, Adorno e Marcuse sobre a relação entre trabalho, sofrimento e sacrifício.

Ao discutir o protótipo do homem burguês na Odisseia de Homero, Horkheimer e Adorno (1947/1985) evidenciam como o trabalho não pode ser descolado da perpetuação da dominação, do sacrifício e do sofrimento. Esses autores mostram que o trabalho está ligado ao sacrifício, relacionado à troca presente nos rituais primitivos, nos quais os homens tinham oferendas advindas do trabalho e a vida de alguém para acalmar a fúria dos deuses, que eram considerados mais fortes. "Sua origem, assim, é a desigualdade entre os homens e deuses, sua aparência, a igualdade expressa pela troca" (Crochik, 2003, p. 63). Essa troca mercantil perde a especificidade do objeto e, consequentemente, torna o sacrifício irracional. O sacrifício transforma-se em fim, deixando escapar a vida que salvou: "A irracionalidade tão invocada do sacrifício exprime simplesmente o fato de que a prática dos sacrifícios sobreviveu à sua própria necessidade racional" (Horkheimer \& Adorno, 1947/1985, p. 60).

Atualmente o indivíduo é submisso a outro deus, o capital. O sujeito é o capital, pois ele determina as ações a ser executadas. A relação indivíduo/sociedade é mediada pelo capital e os que estão na base são a irracionalidade, o lucro e o valor de troca. $O$ trabalho entrega a vida, valorizando o sacrifício, em troca da subsistência. Nesse caso, o sacrifício é perpetuado pela autoconservação e introjetado como fim. Pode-se afirmar que todo sacrifício que não constitui a liberdade do homem, que é anacrônico à vida, é um embuste.

Para Horkheimer e Adorno (1947/1985), o caminho da civilização envolveu o trabalho sacrificado e a impossibilidade do prazer. Ulisses, como proprietário, ao comandar seus companheiros, renuncia à participação no trabalho, é capaz de ouvir o canto das sereias, mas não desfrutá-lo em sua plenitude, pois se amarra ao mastro para ficar impotente: ele se exclui do trabalho e do prazer, realizando a deformação. "Na história das classes, a hostilidade do eu ao sacrifício incluía um sacrifício do eu, porque seu preço era a negação da natureza no homem, em vista da dominação sobre a natureza extra-humana e sobre os outros homens" (Horkheimer \& Adorno, 1947/1985, p. 60).

Os trabalhadores, seguidores de Ulisses, tornando-se práticos, ficavam a remar com todas as forças dos músculos e a olhar para frente, sublimando a distração em mais esforço e com os ouvidos tapados com cera, para não ouvir o chamado sedutor das sereias. Mesmo com toda a proximidade às coisas, eles também não podiam desfrutar do trabalho, porque ele era exercido com coação; foram, então, totalmente subjugados no corpo e na alma ao senhor.

Ao observar essa passagem, percebe-se que o sacrifício do senhor e do servo são distintos. Ulisses é substituído no trabalho e, mesmo conhecendo o que daria prazer, não pode ceder à tentação de se abandonar para não pôr em risco a autoconservação. Ulisses é a vítima 
que se sacrifica pela abolição do sacrifício, mostrando que quanto maior a possibilidade de felicidade, maior também é a recusa pela obstinação. Os trabalhadores não sabem da beleza do canto, pois permanecem moucos, por isso nem chegam a renunciar ao desejo. Eles reproduzem a vida do opressor com a própria vida (Horkheimer \& Adorno, 1947/1985). Essa passagem mostra, portanto, que para realizar um trabalho racional são necessárias a dominação do mundo sensível pelo pensamento e a eliminação da fruição.

Segundo Marcuse (1969/1981), a imposição de ter de trabalhar ou morrer à míngua não pode ser considerada uma atividade prazerosa. Se o trabalho é simplesmente uma atividade para suprir a necessidade imediata de fome e moradia, dentre outras, significa que ele "não tem carência de outra atividade e nem de fruição" (Marx, 1844/2004, p. 141).

Segundo Freud (1930/1997), é possível afirmar que, na atualidade, os que defendem o prazer no trabalho se pautam mais pela sensação ou sentimento de alívio conquistado por evitar o desprazer, afastar o perigo e a frustração e obter segurança (meta negativa) do que por sentir efetivamente o prazer com riscos, por encarar o medo e ousar buscar realizar o desejo (meta positiva). Além do mais, quando o prazer aparece em meio a renúncias fundamentais, mesmo sem querer, ele repete a repressão infligida às próprias aspirações.

Marcuse (1955/1969) confirma os pressupostos de Freud de que não existe uma pulsão inata do homem para o trabalho. O trabalho, como vem se efetivando, exerce uma função nociva para o homem e para a sociedade, pois, ao eliminar as possibilidades de prazer, enfraquece a pulsão de vida, aumenta o sofrimento e possibilita o livre fluxo da pulsão de morte (liberação e expressão dos aspectos destrutivos do homem). De acordo com Marcuse (1955/1969), se para Freud o caráter repressivo está presente tanto na configuração do aparelho psíquico quanto no desenvolvimento da sexualidade como condição da constituição humana, pode-se afirmar que, na atualidade, os critérios que balizam a realidade são tão exagerados que exigem uma repressão exacerbada, são irracionais e perpetuam a submissão do homem. Assim:

\begin{abstract}
Embora qualquer forma do princípio de realidade exija um considerável grau e âmbito de controle repressivo sobre os instintos, as instituições históricas específicas do princípio da realidade e os interesses específicos de dominação introduzem controles adicionais acima e além dos indispensáveis à associação civilizada humana. Esses controles adicionais, gerados pelas instituiç̃oes específicas de dominação, receberam de nós o nome de mais-repressão (Marcuse, 1955/1969, pp. 52-53).
\end{abstract}

A repressão é mais-repressão porque o progresso da sociedade é associado à dominação, que estabelece a força de trabalho como mediação para a conquista do prazer. Nesse processo, a repressão é despersonalizada, "a restrição e arregimento do prazer passam agora a ser uma função (e resultado 'natural' da divisão social do trabalho)" (Marcuse, 1955/1969, p. 91). A mais-repressão inibe as manifestações autênticas e facilita a heteronomia, pois "as restrições perpétuas sobre Eros enfraquecem, em última instância, os instintos vitais, e assim, fortalecem e liberam as próprias forças contra as quais eles foram mobilizados - as de destruição" (Marcuse, 1955/1969, p. 57).

Para Marcuse (1955/1969), o termo mais-repressão focaliza uma repressão diluída, não mais localizada na família, mas nas instituições e relações que constituem o corpo social do princípio de realidade. Ele atinge uma extensão impossível de ser medida e é governada pelo princípio de desempenho, a fim de dar um destaque ao fato de que, sob seu domínio, a sociedade é estratificada de acordo com desempenhos econômicos. No princípio de desempenho, o homem é identificado pela função que exerce, pela sua profissão e pelos comportamentos úteis e competitivos.

Até é possível que o trabalhador, em uma realidade governada pelo princípio do desempenho, sinta prazer em um trabalho bem feito, mas esse prazer ou é "extrínseco (baseado 
na recompensa) ou é a satisfação (em si mesma um indício de repressão) de estar bem ocupado, no lugar certo, de contribuir com sua parcela para o funcionamento da engrenagem" (Marcuse, 1955/1969, p. 191), e não tem relação com a gratificação instintiva primordial ${ }^{3}$, por exemplo,

[...] a datilógrafa que entrega um texto bem copiado, o alfaiate que apresenta um terno bem cortado, o cabeleireiro que monta um penteado impecável, o trabalhador que preenche sua quota - todos poderão sentir prazer num trabalho bem feito (Marcuse, 1955/1969, p. 191).

Contudo, esse prazer é baseado na recompensa ou na expectativa de recompensa. Portanto, o prazer com base no desempenho habilidoso dos órgãos corporais acessíveis ao trabalho não é aquele que erotiza todo o corpo, não é um prazer libidinal. Segundo Marcuse (1964/1973), o prazer que se refere às necessidades impostas aos indivíduos por interesses sociais particulares, reprimindo-os e perpetuando a labuta, a agressividade, a miséria e a injustiça é um prazer falso baseado na sexualidade especializada. Sua realização não é a felicidade, mas a euforia na infelicidade.

Ao mesmo tempo que o trabalho reduz o quantum de energia instintiva canalizada, há uma liberação da energia para a consecução de objetivos individuais e do supérfluo. Nesse processo, existe controle de regiões anteriormente livres da consciência, e se permite o relaxamento dos tabus sexuais e a liberação de Eros ao lazer. Significa que as relações sexuais passam a ser assimiladas às relações sociais e que a tensão entre o princípio do prazer e o princípio da realidade diminui, fazendo que a liberdade sexual se harmonize com o conformismo lucrativo.

Eros segue dois caminhos, indicados por Marcuse (1955/1969): o da sublimação repressiva e o da dessublimação repressiva. A sublimação repressiva, já indicada por Freud, expressa a tensão entre o desejado e o permitido. Nesse movimento, a pulsão é sublimada para objetos socialmente valorizados, à medida que é desviada para um novo objetivo não sexual. A sublimação repressiva ocorreu prioritariamente no início do século $\mathrm{XX}$, quando, com o conhecimento de ditames e normas, o indivíduo elaborava estratégias para burlá-las, criava respostas à realidade e buscava satisfações substitutivas nos diversos âmbitos sociais. Nesse sentido, a sublimação era moldada segundo os requisitos sociais repressivos.

Na dessublimação repressiva, predominante na sociedade contemporânea, a pulsão não tem mais necessidade de ser desviada, em razão de uma cultura liberada, na qual os prazeres consentidos e pagos se relacionam à coesão e ao contentamento. A sexualidade especializada é gratificada e, assim, o corpo deserotiza-se. A repressão não se volta mais contra os desejos sexuais; pelo contrário, há um processo de valorização dos desejos sexuais, de forma a exacerbar a sexualidade genital, em detrimento da sexualidade erotizada, o que enfraquece a libido. A cultura oferece as bases para a satisfação imediata e, assim, institucionaliza a dessublimação. $\mathrm{O}$ homem é condicionado a aceitar de forma espontânea o que é oferecido, "considerando que a maior liberdade compreende mais uma contração do que a extensão e o desenvolvimento de necessidades instintivas, ela age mais a favor do que contra o status quo de repressão geral podese falar de dessublimação institucionalizada" (Marcuse, 1964/1973, p. 84). Nesse contexto,

[...] o Princípio do Prazer absorve o Princípio da Realidade; a sexualidade é liberada (ou antes, liberalizada) sob formas socialmente construtivas. [...] Assim, diminuindo a energia erótica e intensificando a energia sexual, a realidade tecnológica limita o alcance da sublimação. Reduz também a necessidade da sublimação. No mecanismo mental, a tensão entre o que é desejado e o que é permitido parece consideravelmente reduzida e o Princípio da Realidade não mais parece exigir uma transformação avassaladora e dolorosa das necessidades instintivas. $\mathrm{O}$ indivíduo deve adaptar-se a um mundo que não parece

3 Ligada à satisfação dos próprios impulsos, a necessidades e a faculdades daquele que realiza. 
exigir a negação de suas necessidades íntimas - um mundo que não é essencialmente hostil (Marcuse, 1964/1973, pp. 82-83).

Para obter satisfação, o indivíduo não precisa mais se opor à realidade, pois a libido assim administrada pode ser responsável

[...] por muito da submissão voluntária, [...] da harmonia preestabelecida entre necessidades individuais e desejos, propósitos e aspirações socialmente necessários, [...] satisfação de um modo que gera submissão e enfraquece a racionalidade do protesto (Marcuse, 1964/1973, p. 85).

Oferece-se uma relação rápida e superficial dos objetos para que o indivíduo tenha a impressão que algo distinto está sendo ofertado, quando, na verdade, as coisas só se diferenciam no detalhe, possuindo a mesma substância. Assim,

[...] reações rápidas, sem a mediação do que constitui o indivíduo, não restauram a espontaneidade, mas estabelecem a pessoa como instrumento de medida possível e decifrável pela autoridade central. Quanto mais imediata é a sua decisão, tanto mais profundamente sedimentada está, na verdade a mediação: nos reflexos de pronta resposta, desprovidos de resistência, o sujeito extinguiu-se por completo (Adorno, 1951/1993, p. 202).

Se antes o trabalho intelectual, artístico e a cultura estavam situados em um patamar mais elevado do que a estrutura econômica e se contrapunham à racionalidade tecnológica, atualmente eles são considerados pelo critério de produtividade.

A racionalidade do trabalho também está presente nos momentos de ócio e de lazer. Geralmente, o tempo livre é o complemento do trabalho e sua existência consiste em produzir valor (Adorno, 1951/1993, p. 154). Aqueles que não observam essas questões podem fazer uma apreensão imediata de que a exclusão do mercado de trabalho gera desespero, depressão e suicídio, por isso, o trabalho é formativo. A sociedade adestra as pessoas para um mercado de trabalho, e o indivíduo, por sua vez, só se sente encontrado e aceito se tem uma ocupação:

Minha mãe deseja que eu me ocupe de alguma coisa; isso me fez rir. Não estou eu, então, ocupado neste momento? Seja em contar grão de ervilhas, ou lentilhas, no fundo não é a mesma coisa? Tudo neste mundo leva às mesmas mesquinharias (Goethe, 1774/2002, p. 256).

\section{Considerações finais}

Essa discussão aponta o equívoco de estabelecer a formação do indivíduo na racionalidade do trabalho, ou seja, na dinâmica da produção e do consumo. Muitos falam que, no desemprego estrutural, a sociedade não é mais regida pela centralidade do trabalho, esquecendo que as reestruturações do capital e, consequentemente, do trabalho propiciaram a crise do emprego, o desemprego e as formas de lazer. Não é o caso de ressignificar a categoria trabalho para a atualidade. Não é o significado que o trabalhador atribui ao seu produto que vai dar ao trabalho um teor transcendente que extrapola a realidade, mas a análise das contradições materiais de existência do trabalho.

No capitalismo tardio, que apresenta uma imensa elevação do potencial técnico e de quantidade de bens de consumo, uma realidade, na qual "as relações de produção se revelaram mais elásticas do que Marx imaginava”, a ênfase às posições de patrão e de trabalhador no 
processo de produção, em última instância, no poder de dispor ou não sobre os meios de produção, é insuficiente para entender as relações de dominação. Marcuse e outros teóricos da Escola de Frankfurt diferenciam dominação de exploração. O fenômeno da dominação é mais antigo e mais enraizado no homem, por isso mais difícil de ser solucionado, porque a exploração pode terminar, mas o desejo de controlar e o desejo de servir permanecem, havendo diferenciação entre libertação política e libertação psíquica. Levando em conta esses elementos, prega-se a substituição da crítica à economia política pela crítica à civilização técnica, o que envolve a reprodução das condições servis ou de dominação pelos dominadores e dominados, mesmo que não existam mais condições objetivas para tal. Nesse caso, a preocupação com a dominação extrapola a consciência de classe e enfoca a consciência revolucionária, que inclui os mecanismos inconscientes, os quais entram em ação e anulam e neutralizam a emancipação (Matos, 1998).

Mesmo que o mundo administrado tente atenuar as resistências e os conflitos advindos do sacrifício e do sofrimento no trabalho, faz parte do psicólogo do trabalho a responsabilidade de revelar essas contradições. É fundamental ter cuidado para que a categoria trabalho não termine pairando como um espectro na realidade, algo que dispõe de uma aura quase romanceada.

Adorno (1947/1986b) defende que a discussão do capitalismo tardio precisa ser: "desenvolvida teoricamente e não só através da apresentação dos fatos que, por sua vez, é claro, contribuem de muitos modos para a crítica, mas que, segundo a Teoria Crítica, também encobrem a estrutura" (Adorno, 1947/1986b, p. 63). Nesse sentido, reconhecer e oferecer resistência aos padrões monopolistas que afetam as mentes dos indivíduos é fundamental. Por mais insuperáveis que sejam os padrões, é necessário contribuir com meios que não sucumbam, eles próprios, ao caráter de fetiche. Então, deve-se ter cuidado para que o fetichismo dos fatos não corresponda ao fetichismo das leis objetivas. As leis objetivas não devem ser divinizadas, mas criticadas em relação à aparência de que o individual e o concreto já determinam o curso do mundo.

\section{Referências}

Abbagnano, N. (2003). Dicionário de filosofia (A. Bosi trad.) São Paulo: Martins Fontes.

Adorno, T. W. (1986a). Acerca de la relación entre sociología y psicología. In H. Jensen (Org.), Teoría crítica del sujeto (H. Jensen, trad.) (pp. 36-83). Buenos Aires: Siglo XXI. (Trabalho original publicado em 1955).

Adorno, T. W. (1986b). Capitalismo tardio ou sociedade industrial. In G. Cohn (Org.), Theodor W. Adorno: grandes cientistas sociais (pp. 62-75). São Paulo: Ática. (Trabalho original publicado em 1947).

Adorno, T. W. (1993). Minima moralia (L. E. Bicca, trad.) (2a ed.). São Paulo: Ática. (Trabalho original publicado em 1951).

Adorno, T. W. (1995). Palavras e sinais: modelos críticos (M. H. Ruschel, trad.) (vol. 2). Petrópolis, RJ: Vozes. (Trabalho original publicado em 1969)

Chaves, J. de C. (2007). A liberdade e a felicidade do indivíduo na racionalidade do trabalho no capitalismo tardio: a (im)possibilidade administrada. Tese de doutorado em Psicologia Social Não-Publicada, Programa de PósGraduação em Psicologia Social, Pontifícia Universidade Católica de São Paulo (PUC-SP), São Paulo.

Crochík, J. L. (2003). Notas sobre trabalho e sacrifício. Trabalho, Educação e Saúde, 1 (1), 61-73.

Engels, F. (2000). A dialética da natureza (J. B. S. Haldane, prólogo) (6ª ed.). Rio de Janeiro: Paz e Terra. (Trabalho original publicado em 1870)

Forrester, V. (1997). O horror econômico (A. Lorencini, trad.) (7ª ed.). São Paulo: Unesp.

Freud, S. (1997). O mal-estar da civilização (J. O. de Aguiar Abreu, trad.). Rio de Janeiro: Imago. (Trabalho original publicado em 1930).

Goethe, J. W. (2002). Fausto e Werther (A. Maximiliano, trad.). São Paulo: Nova Cultural. (Trabalho original publicado em 1774).

Hesíodo. (2002). Os trabalhos e os dias (M. C. N. Lafer, trad.) (4⿳亠丷厂 ed.). São Paulo: Iluminuras. (Trabalho original publicado em 1989). 
Horkheimer, M. (2002). Eclipse da razão (S. U. Leite, trad.). São Paulo: Centauro. (Trabalho original publicado em 1968).

Horkheimer, M. \& Adorno, T. W. (1985). Dialética do esclarecimento: fragmentos filosóficos (G. A. de Almeida, trad.). Rio de Janeiro: Jorge Zahar. (Trabalho original publicado em 1947).

Imbrizi, J. M. (2005). A formação do indivíduo no capitalismo tardio: uma análise de estudos que vinculam a esfera subjetiva ao mundo do trabalho. Tese de Doutorado, Programa de Pós-Graduação em Educação: História, Política e Sociedade, Pontifícia Universidade Católica de São Paulo, São Paulo.

Lafer, M. C. N. (2002). Introdução. In Hesíodo, Os trabalhos e os dias (M. C. N. Lafer, trad.) (4⿳亠丷a ed.). São Paulo: Iluminuras. (Trabalho original publicado em 1989).

Marcuse, H. (1969). Eros e civilização (A. Cabral, trad.) (4⿳⺈冂䒑 ed.). Rio de Janeiro: Zahar. (Trabalho original publicado em 1955).

Marcuse, H. (1973). A ideologia da sociedade industrial: o homem unidimensional (G. Rebuá, trad.) (4a ed.). Rio de Janeiro: Zahar. (Trabalho original publicado em 1964).

Marcuse, H. (1978). Razão e revolução (M. Barroso, trad.) (2 ${ }^{\underline{a}}$ ed.). Rio de Janeiro: Paz e Terra. (Trabalho original publicado em 1941).

Marcuse, H. (1981). Ideias sobre uma teoria crítica da sociedade (F. Guimarães, trad.) (2aㅡ. ed.). Rio de Janeiro: Zahar. (Trabalho original publicado em 1969).

Marx, K. (2004). Manuscritos econômicos-filosóficos (J. Ranieri, trad.). São Paulo: Boitempo. (Trabalho original publicado em 1844).

Matos, O. (1998). Vestígios: escritos de filosofia e crítica social. São Paulo: Palas Athena.

Pedrosa, J. G. (2003). Trabalho e educação no capitalismo tardio: crítica do trabalho hipostasiado. Tese de Doutorado, Programa de Pós-Graduação em Educação: História, Política e Sociedade, Pontifícia Universidade Católica de São Paulo, São Paulo.

Resende, A. C. A. (2001, julho/agosto). Subjetividade em tempos de reificação: um tema para a psicologia social. Estudos: Vida e Saúde, 28 (4), 511-538.

Rouanet, S. P. (2001). Teoria crítica e psicanálise. Rio de Janeiro: Tempo Brasileiro.

\section{Endereço para correspondência}

julichcastro@gmail.com 